\title{
Science Spaces as 'Ethnoscapes': Identity, Perception and the Production of Locality
}

\author{
Dave Valler ${ }^{1, *(D)}$, Nicholas Phelps ${ }^{2}$, Julie Tian Miao ${ }^{2}{ }^{(}$, Paul Benneworth ${ }^{3}(\mathbb{D}$ and \\ Franziska Eckardt ${ }^{4}$ \\ 1 School of the Built Environment, Oxford Brookes University, Headington Campus, Oxford OX3 0BP, UK \\ 2 Faculty of Architecture, Building and Planning, The University of Melbourne, Melbourne, \\ VIC 3010, Australia; nicholas.phelps@unimelb.edu.au (N.P.); julie.miao@unimelb.edu.au (J.T.M.) \\ 3 Department of Business Administration, Western Norway University of Applied Sciences, Inndalsveien 28, \\ 5063 Bergen, Norway; paul.benneworth@icloud.com \\ 4 Centre for Higher Education Policy Studies, University of Twente, Building 10 Ravelijn, Drienerlolaan 5, \\ P.O. Box 217, 7500 AE Enschede, The Netherlands; f.eckardt@utwente.nl \\ * Correspondence: dvaller@brookes.ac.uk; Tel.: +44-1865-483971
}

Received: 15 January 2019; Accepted: 26 January 2019; Published: 29 January 2019

\begin{abstract}
Science and technology spaces around the world are, simultaneously, major physical, technological and symbolic forms, key elements of economic strategy, and sites of international labour movements and knowledge transfer. They are thus the product of multiple imaginations, with multiple, potentially divergent, objectives. In this paper, we compare three international science spaces as 'ethnoscapes', emphasising the distinctive perceptions, cultures and identities amongst international science and technology migrants and visitors at these sites. This, we contend, sharpens a sense of the 'international-ness' of science spaces in various dimensions, given the particular experiences of scientific migrants and visitors moving into different nations, locations and facilities, their roles in constructing international communities, and their navigation of alternative spaces. It also offers insight into the production of contextual (rather than spatial or physical) localities, as international scientists and technologists experience and constitute larger formations, building on their perceptions of varied and interacting science 'scapes.
\end{abstract}

Keywords: Science 'scapes; ethnoscapes; transnationalism; locality; scientific culture and identity

\section{Introduction: Science 'Scapes and Ethnoscapes}

Science and technology spaces around the world operate as loci for transnational flows of scientific labour, technological and entrepreneurial know-how, development practice and symbolic capital. Yet despite a wealth of contemporary interest in these discrete aspects and their associated transnational flows (see inter alia [1-6]) there has been little attempt to conceptualise the multiplex nature of science spaces per se or to engage the complex interactions of the various spheres. In this paper we propose some initial movement towards such a synthesis, focusing on a notion of science 'scapes. Building on the work of Arjun Appadurai [7-9] (see further below) the concept of science 'scapes emphasises the fluid interaction of transnational cultural flows, in this instance along three main dimensions: how science spaces are imagined and experienced as physical forms, or 'technoscapes', reflecting the global circulation of built environment and real estate formats; how they operate as science diplomacy, or 'ideoscapes', projecting soft power; and as patterns of transnational labour mobility and knowledge transfer, or 'ethnoscapes'. These inter-relating 'scapes become the context within which a range of actors constitute their various identities and relations, and imagine their futures-in short, they engage in various forms of 'place-making'. In this initial 'conceptual-framing' paper we focus on science 
spaces as ethnoscapes, reflecting the critical importance of international scientific labour in science spaces, and emphasising inter alia the construction of identities and patterns of meaning amongst international scientists, the diverse experiences of international scientific work, distinctive perceptions of spatial imaginaries and built form, and differentiation amongst interpretations of particular science spaces. In this way, we seek to move beyond more uni-dimensional readings of science spaces in the existing literature.

Clearly, by virtue of their highly-skilled labour requirements, science and technology spaces across the globe attract variably internationalised workforces. In the forerunner case of Silicon Valley, for example, more than one-half of business start-ups between 1995 and 2005 involved a foreign-born scientist or engineer, with one-quarter including an Indian or Chinese immigrant [10]. Elsewhere the picture is less dramatically globalised, though science and technology spaces act as key loci for global-regional processes of 'brain drain' and 'brain circulation'. Filatotchev et al [11] report that more than 275,000 overseas Chinese scientists and students had returned to China by 2006, amongst which 5000 returnees had set up 2000 new high-tech firms in Zhongguancun. And at Taiwan's Hsinchu Science and Technology Park it was reported that in the year 2000 alone over 5000 scientists returned from abroad (predominantly the US), while 113 of the 289 Hsinchu-based companies were started by US-educated Taiwanese, and 70 of the companies also had offices in Silicon Valley [3] (p. 256).

These transnational labour movements and entrepreneurial flows have attracted considerable academic and policy interest (see inter alia: [11-17]). A study by the Royal Society [18], for example, found that cross-border scientific collaboration was increasing, that it disproportionately involved scientists with diaspora ties, and that it offered potential to improve the quality of science. Saxenian [15] has drawn particular attention to the 'new argonauts'-foreign-born scientists, engineers, entrepreneurs, managers, lawyers and bankers-who facilitate decentralised flows of skill, technology and capital between their domestic and host nations, with significant implications for global development. Understanding global science and high-tech spaces therefore requires particular sensitivity to processes of transnational mobility and linkage, and mechanisms for knowledge transfer $[19,20]$.

Rather less developed in the literature are questions of culture, including for example the construction of new or hybrid identities amongst international scientists and their distinctive experiences and perceptions [21,22]. Yet this is integral to an understanding of the global character of such spaces, their respective positions in international divisions of labour, and their wider roles in national economic strategy and science diplomacy [23]. Indeed, the perspectives of international scientists and technologists offer significant potential to sharpen understanding of the 'international-ness' of science spaces in various dimensions, given their particular experiences of moving into different nations, locations and facilities, their roles in constructing international communities, and their navigation of alternative spaces.

To begin to theorise and inform these new identities, experiences and meanings, we appeal to the notion of science spaces as 'ethnoscapes' or 'landscapes of group identity, no longer bound to certain territorial locations' [7] (p. 48), emphasising the distinctive and variable ways in which different groups of people understand and experience their worlds. This derives from Arjun Appadurai's [8] formative examination of a global cultural economy comprised of multiple 'scapes, or interrelating framework of global cultural flows. Appadurai highlights five key dimensions: ethnoscapes (essentially the moving landscape of persons); mediascapes (global media and moving images, and information); technoscapes (mobile technologies, in the widest sense); finance-scapes (flows of capital); and ideoscapes (mobile images, meanings, and political messages and ideologies). The common suffix 'scape denotes the fluidity, dynamism and irregularity of these various dimensions, and importantly their dependence on perspective:

"these are not objectively given relations that look the same from every angle of vision but, rather,... they are deeply perspectival constructs, inflected by the historical, linguistic, and political situatedness of different sorts of actors: nation-states, multinationals, diasporic communities, as well as subnational 
groupings and movements (whether religious, political, or economic), and even intimate face-to-face groups, such as villages, neighborhoods, and families. Indeed, the individual actor is the last locus of this perspectival set of landscapes, for these landscapes are eventually navigated by agents who both experience and constitute larger formations, in part from their own sense of what these landscapes offer". [8] (pp. 296-297)

Crucially, for Appadurai, it is against the backdrop of these fluid 'scapes that actors imagine their futures, within their own particular historical contexts. They form the 'building blocks' for multiple 'imagined worlds' [8], a conceptual stance which has clear resonance with the experience of international migrant scientists, given their distinctive personal biographies, movements and perspectives, their frequent integration into international scientific networks and their construction of new communities at a variety of scales. Thus, it becomes feasible from this vantage point to explore the dynamics of various 'place-making' flows, from the personal to the institutional and from the local to the national, transnational, global, and diasporic [24] (p. 754). This, in turn, implies a multi-dimensional focus on science and technology spaces, which are produced as contextual (rather than physical or spatial) 'localities' or shared 'structures of feeling' [9] by multiple actors (central and local governments, private developers, universities, multi-national firms, research institutes, individual scientists and scientific teams) operating at multiple scales and with multiple, potentially divergent, objectives. Also, in line with Appadurai's theoretical emphasis, it allows for the privileging of mobile groups such as international scientific labour, whose distinctive perspectives and perceptions produce novel insights into such place-production.

In this paper we develop a comparative focus on science spaces as 'ethnoscapes'. Appadurai [7] (p. 48) elaborates the ambiguous notion of ethnoscapes in two key dimensions, first as 'landscapes of group identity', and second as processes of perception and perspective. Thus, we adopt a dual focus on the nature of international scientific identities across our respective cases (Section 3 below) and distinctive international perceptions of the varied 'technoscapes' (Section 4). Research was undertaken at three contrasting science spaces, namely: Science Vale Oxford (SVO) in southern Oxfordshire, England; Kennispark Twente in Enschede, eastern Netherlands; and Tsukuba Science City (TSC), in Ibaraki Prefecture in the northern Kantō region of Japan. We report here on an initial tranche of over 40 semi-structured interviews with primarily expatriate international scientists and technologists undertaken in 2015 and 2016, designed to draw out distinctive perceptions, cultures and identities amongst international migrants and visitors at these sites. Interviews at Kennispark included 10 international knowledge migrants (seven foreign scientists and three foreign post-doctoral employees) and an additional 10 interviews with domestic employees of Kennispark Twente, the University of Twente and the Municipality of Enschede. A total of 15 interviews were conducted with international scientists at Science Vale Oxford, 12 based at leading big science installations (see below), together with a further three interviewees across other hi-tech firms and research institutes. In Tsukuba eight interviews were conducted with overseas researchers of all ranks at various national research institutes and the University of Tsukuba. Also here, 10 interviews were undertaken with Ibaraki prefectural and central government officers and planners in Tsukuba, Tokyo and Mito who were responsible for the original planning of Tsukuba, as well as with representatives from the main coordinating institutions such as Tsukuba Centre for Institutes and Tsukuba Center Inc. Interview schedules built around a central core of questions derived from the 'Global Science Scapes' international network sponsored by the Leverhulme Trust, customised in relation to the particular cases. Analysis then adopted a broad narrative technique to address the complexity and subtleties of questions around individual identities and perceptions. It was important here to gather insights about the ways in which actors made and used narratives to describe and interpret the world around them, largely through forms of story-telling. Case studies were then drafted separately in order to enhance their internal validity and to reflect the nature of individual cases, with comparative themes to emerge through subsequent reflection, writing and publication. 
Prior to Sections 3 and 4, however, Section 2 sets the respective scenes by summarising the nature and evolution of the cases as physical, technological and developmental forms-characterised broadly as 'technoscapes' - and as ideational entities, or 'ideoscapes'.

\section{Science Vale Oxford, Tsukuba Science City and Kennispark Twente as Technoscapes and Ideoscapes}

The physical, technological and developmental contexts-'technoscapes'-at SVO, Kennispark and TSC reflect the complex, dynamic and path-dependent processes through which they have been imagined, constituted and re-imagined over time. They must be understood, therefore, with reference to the deeper currents of national political-economic strategy which underpin their development. Yet they also refract other technological, socio-economic and cultural processes operating across varied scales, and establish particular forms of historical legacy and path-dependency. Here, we briefly summarise key aspects of each case, and identify important distinctions and commonalities between them.

\subsection{Science Vale Oxford}

SVO is a relatively recent entity (introduced in 2008 initially as 'Science Vale UK') encompassing three established but diverse high-tech employment centres in the southern part of Oxfordshire, UK: Harwell Oxford, Culham Science Centre and Milton Park. Harwell was historically a major government site for civil nuclear power research under the UK Atomic Energy Authority (UKAEA), but has since transformed into a leading centre of science and technology business which now houses the Diamond Synchrotron ('Diamond'), the UK's largest investment in science for 40 years, and ISIS, the world's largest pulsed neutron source. It is also home to the UK Science and Technology Facilities Council (STFC), the Rutherford Appleton Laboratory, the UK Medical Research Council, and the European Space Agency Space Centre. Culham Science Centre, initially an off-shoot of the Harwell civil nuclear power programme, has been the centre of the UK's nuclear fusion research programme and currently houses the world's largest fusion experimental facility, the Joint European Torus (JET— to be superseded from 2020 by ITER, International Thermonuclear Experimental Reactor, in in Saint-Paul-lès-Durance in the south of France). Milton Park, meanwhile, is one of Europe's largest multi-use business parks. Previously a railway depot for military supplies and then an industrial estate it has evolved into a mix of office, industrial and science park space with particular strengths in the bio-tech and ICT sectors and on-site business incubation facilities including an innovation centre for small and growing companies.

As this initial description suggests, the history and nature of SVO and its constituent science spaces is complex and dynamic. Harwell, a former RAF base, was imagined in the immediate post-war years as a site of special importance both for the development of British science and for the future of the nation. As a leading-edge establishment in atomic science its work was shrouded in secrecy, its specialist staff secluded in the cloistered, almost monastic surroundings of an isolated national laboratory [25], and its physical form a peculiar mix of war-time military legacy, nascent industrial-scale 'big science', and the cossetted academic setting of the established (British) university. Culham, as an off-shoot of Harwell and also located on a former military site, had similar characteristics, though it was custom-built as a laboratory and more obviously modelled on a university environment, while Milton Park's evolution as an industrial trading estate and then mixed-use business and science park was clearly distinct from the other 'big science' sites.

From the late 1960s Harwell began a major transformation as the atomic energy programme gradually gave way to a new and more diversified 'industrial' mission to support British competitiveness [26]. By the 1990s attention was switched to decommissioning and environmental restoration, and the development of part of the site as an international business centre. Meanwhile, nuclear fusion research was further extended at Culham with JET, the world's largest operational magnetic confinement plasma physics experiment, under construction at the Culham Centre for Fusion Energy from 1978 and the first plasma experiments conducted in 1983. 
In contrast to the post-war national atomic research ideoscape which motivated the construction of Harwell and then Culham, the formation of SVO has been a post-hoc assemblage and rationalisation of the existing southern Oxfordshire technoscapes driven primarily by local actors. Indeed, the origins of SVO as an idea derive most directly from local political circumstances in the county of Oxfordshire and competition amongst local authorities for resources, while obviously appealing more generally to the wider positioning of the UK within a global knowledge-based economy. In this sense the construction of 'Science Vale Oxford' as an entity reflects very specific local political conditions, as well as an attempt to engender coherence across complex and diverse historical foundations. The science parks themselves are disparate entities, quite distinct in terms of their character and their future development requirements. They are also physically separated from each other across 10 miles of relatively open countryside. Imagining and projecting a cohesive story across such diversity is a significant challenge, exacerbated by different patterns of ownership and local government arrangements across the respective sites. In many respects, the parks are individual and differentiated 'clumps' of high-tech activity projected onto an historic rural setting, rather than integrated and planned 'campus-garden' developments [27,28].

\subsection{Tsukuba Science City}

In contrast to the retro-fitting of a new collective identity onto the constituent elements of SVO, TSC stands as one of the prime examples of deliberately planned concentration of scientific research most notably pursued among East Asian developmental states. This formed part of extensive government intervention in Japan through a planned process of national economic transition and catch-up, in parallel with other developmental states including South Korea and Taiwan. Planning for Tsukuba took place during the 1960s, with Cabinet approval granted in 1963 and initial construction progressing from that point into the 1970s. The creation of Tsukuba was controversial, however, both among the agricultural communities located here $50 \mathrm{~km}$ northwest of Tokyo, and within the Japanese planning, education and scientific communities ([29], p. 70, [30], p. 455), particularly given the remoteness of the area and the perceived over-concentration of research institutes and funding in the new city at the expense of established universities across Japan. Nevertheless, the plan prevailed and central government dictated that as many as 43 national level institutes relocate to the new science city. 29 national institutes exist in Tsukuba today as a result of subsequent rationalisations and consolidations covering the fields of education, construction, science and engineering, and biological sciences, and institutes among which JAXA (Japan Space Agency), KEK (High Energy Accelerator Research Organisation), AIST (National Institute of Advanced Industrial Science and Technology) and NIMS (National Institute of Material Science) are notable [31]. Additionally, a first industry park was completed in 1982 and by today there are 150 private companies located on 9 industry and research parks.

Alongside other examples (such as Hsinchu in Taiwan and Daedeok Innopolis in South Korea), TSC was conceived as a national-level concentration of research institutes aimed at modernising the production of scientific knowledge. While the primary motivation here was to relocate population away from Tokyo as part of a post-war national project to foster dispersed infrastructure and industrial development, a large number of government research institutions located in and around the capital were in need of substantial improvement and updating as part of Japan's industrial and economic development [32] (p. 1239). Thus, a powerful national ideoscape drove development on a monumental scale, with $\$ 5$ bn public investment over the first 20 years, covering in total approximately 2700 hectares (around 1500 hectares designated for research and educational buildings) and a population building to around 225,000. Moreover, nearly half of Japan's public research and development budget has been spent in TSC.

As a prime example of the international-campus-garden-suburb (ICGS) model of science park development [28], the technoscape of TSC was a 'carefully planned and controlled experiment of an entirely new kind for modern Japan' [33] (p. 261). It effectively erased the previous agricultural setting 
in constructing this wholly new garden-city form, ultimately, in the words of prominent Japanese architect Isozaki Arata, reflecting the monumentality of the Japanese national state in a 'desolate modern city designed and built by the textbook' [33] (p. 50). Yet beyond the sleek modernity of the science city, the wider physical landscape combines rural, urban and suburban elements, with city mayor Kenichi Ichihara describing Tsukuba in 2010 as follows:

"Part of it is a metropolitan city, another part is like a provincial town, and still other areas resemble the original farming communities with old-fashioned village schools and the like. There's nowhere like it in Japan."

Indeed, TSC evolved through time to its current urbanised science-city form, building from an under-developed rural fabric and a socially-sterile context in the 1960s and 1970s. This had proved unattractive to many scientists and others who continued to commute from Tokyo. Subsequently, however, two notable turning points helped to extend the project in the way initially envisaged in the 1960s. The first came with the International Science and Technology Exposition in 1985 which was accompanied by better road links to Tsukuba and enhanced international visibility for the city, helping to attract private sector investment in research laboratories. As the development of Tsukuba city gathered pace and as the Japanese economy boomed, the presence of national research institutes did indeed attract the research laboratories of major Japanese and foreign companies such as Intel. Private companies established branches as listening posts for research being carried out in national research institutes in the pre-internet era. Hall and Castells [29] (p. 74) noted how little or no manufacturing was relocated by these companies to Tsukuba, however, and interview evidence suggests that even the research institutes themselves were effectively branches responsible to their head office Ministries in Tokyo, with little interaction between the staff of laboratories, institutes and universities. Thus, TSC has not benefitted from large scale localised technological spill-overs and continues to be largely off the radar of international property investors.

A second turning point was the completion of the Tsukuba Express (TX) railway line in 2005, greatly increasing TSC's accessibility to Tokyo compared to the previous JR line. This extended future growth potential and reinforced growth plans following two mergers involving five neighbouring municipalities in 1987 and 2002. However, the implications of an expanded TSC are rather ambiguous. The fact that much of Tsukuba outwith the original TSC core now operates as a dormitory for Tokyo has implications for the uniqueness of the 'science city'. Moreover, although greater accessibility to Tokyo and the development potential of Tsukuba have offered the promise of 'Japan's Silicon Valley', a number of private enterprises have actually left Tsukuba as digital and physical connectivity has obviated the need for physical proximity to Tsukuba's institutes (Executive Managing Director, Tsukuba Centre Inc., 6 June 2016).

\subsection{Kennispark}

Kennispark is a 180-hectare site located in the Dutch Twente region, close to the German border. It was established around 2000, building on the regionally-located University of Twente (UT) and neighbouring Business and Science Park (BSP) constructed in the 1980s. Approximately 8000 people work in Kennispark and more than 700 spin-off firms are rooted in the UT, one of the most entrepreneurial universities among Europe [34].

In contrast to the national ideoscapes which originally underpinned the big science centres at SVO and TSC, Kennispark was conceived as a localised entrepreneurial high-tech ecosystem building on an ability to take knowledge from the university, other knowledge institutions and firms, and embody that into spin-out firms which are in various ways 'born global'. These involve knowledge and intellectual property that has been developed in international collaborative research projects, often spanning the public and private sector. They attract a range of investments, often leveraged by local venture capital and debt finance, but also increasingly able to lure investments from outside the region, both in the Netherlands, but also - with the location of a branch of Cottonwood Technology Fund 
in Enschede-internationally and from Silicon Valley. Some of these firms go on to become world leading businesses, such as the internet companies booking.com and Thuisbezorgd.nl (takeaway.com). Thus firms, knowledge institutions and other public actors such as the municipality and Province work to ensure that there are synergies which create a positive 'entrepreneurial ecosystem' that supports the further development of high-technology firms.

In line with this strategic imagination, the physical form of Kennispark reflects the fusion of two distinct elements, the university campus and the adjacent BSP. Originally established in 1961, the UT was an attempt by policy makers to protect and revive the region economically against the demise of the local textile industry. The site was developed as the first university campus in the Netherlands on an almost pristine country estate, with inspiration drawn from the U.S., in particular from Harvard University, in terms of the physical layout necessary to achieve a degree of intimacy and community coherence within a city with limited experience of accommodating students. Subsequently, in the 1980s the business park was developed to the south of the main Enschede-Hengelo trunk road, as the University underwent a fundamental re-evaluation of its philosophy, being forced to confront the disappearance of the local textiles industry which it had been expected to support. To this end, the university reinvented itself as an 'entrepreneurial university', and in 1987 changed its name to the University of Twente, taking the entrepreneurial strapline as its institutional motto. Active engagement with regional industry, regional policy makers, municipalities, and regional and national actors finally led to the creation of Kennispark, encouraging the connection of companies located in the earlier established BSP with the university campus. From 2001 the decision was taken to physically plan these two spaces as a single site, and to integrate them around a single logic. This has included the removal of the Viaduct flyover which had physically separated the university campus and the BSP, and the renovation of the Chemical Technology building as The Gallery, a new high-technology space.

Gradually, then, the re-imagining of the university and its changing regional role has been the ideoscape motivating the development of the area, as the initial rationale for a form of campus-based sequestered cloistering of newly attracted staff and students in an old industrial region gave way to a regionally-oriented entrepreneurial project, informed by various strands of thought around high-tech development including business incubation, wider technopole-formation, more flexible campus master-planning, and high-value business property development. A key element of the Kennispark project has been an attempt locally to position the Twente region and the Enschede functional region as a national intellectual infrastructure suitable for strategic infrastructure investment, thereby casting Kennispark as an explicit political project within the Netherlands, not least as a means of contradicting a national economic development narrative which sees the east of the Netherlands as being a 'backward place'. For local partners, the key issue for Kennispark was as a motor of economic development and growth, the initial promise to create 10,000 high technology jobs by 2020, and to counter the perception at higher governmental levels of the region as a peripheral node in a wider knowledge trunk infrastructure. To some extent Kennispark has been successful in positioning itself within the national policy discourse as part of the Dutch national knowledge infrastructure, although this has remained at the level of particular investments. However, the central state in the Netherlands has generally been resistant to these efforts to recognise Kennispark as something special and has tended to deal with Kennispark-Twente-Overijssel in the same way as other regions.

In summarising Section 2, one immediate commonality amongst the cases concerns relations of centrality and peripherality. In each case there is something of a tension between the ideoscapes which have centered the respective formations in national and regional strategy, and the more marginal geographical locations in which they have evolved. In turn these tensions, as we will show, inform international scientific identities and perceptions.

In SVO, the quiet countryside and historic villages of southern Oxfordshire provide an incongruous backdrop to 'a global hot spot for enterprise and innovation in science, high technology and the application of knowledge' (http://www.sciencevale.com/). Yet this largely rural and somewhat isolated area has been a pivotal part of U.K. science infrastructure, with locations such 
as Harwell becoming ingrained in the national psyche as a physical encapsulation of British science. Notwithstanding the local impulses which prompted the introduction of SVO, the area undoubtedly resonates with the thrust of contemporary national economic strategy and the emphasis placed on science within an overall global competitiveness agenda. Science-based development also plays a prominent role in the cultivation of symbolic or soft power, and the science sites of southern Oxfordshire are prominent in Government policy and marketing. In these terms the facilities at SVO are demonstrably perceived as critical elements of the UK knowledge-based economy and central to the nation's scientific profile and global economic competitiveness. Yet, there is also a clear sense that both SVO as a whole and the major constituent sites suffer from comparative weaknesses in terms of imaging and identity, in part betraying the localist foundations of the SVO concept in particular. Indeed, it is apparent that SVO per se is relatively little known or understood internationally, while the major research institutes at Harwell and Culham have global reach within their own specific scientific communities.

In Tsukuba, the initial ambition of the developmental-state era, to create a comprehensive and integrated 'science city' adjunct to greater Tokyo, has given way [35]. Indeed, against the background of economic slowdown and urban renaissance, the Japanese central government has abandoned aspirations for balanced national development, seeking to strengthen its international competitiveness by refocusing planning attention on a greater Tokyo, and on its inner suburban centres in particular. In part the increasing peripheralisation of Tsukuba reflects a post-developmental strategic objective to overcome the separation between science and commercialisation rooted in developmentalism. Thus, the culture of Tsukuba, oriented towards pure research, has been distanced from commercialisation taking place in Tokyo.

Consequently, efforts to commercialise the results of pure research have increased in Tsukuba, also coinciding with the greater accessibility to Tokyo afforded by the TX line. The creation of the Tsukuba Science City Network in 2004 was precisely for the purpose of speeding up commercialisation, as was the creation of the Tsukuba International Strategic Zone in 2011, led by the Tsukuba Global Innovation Promotion Agency. The research institutes and universities in Tsukuba have incentivised employment contracts and funding regimes to stimulate more applied research and encourage more interactions with the private sector, though this transformation will take time to generate significant effects. However, the general story here has been one of rationalisation out of Tsukuba and re-centralisation into Tokyo, effectively reinforcing Tsukuba's perceived peripherality, despite its gradual physical integration into the metropolis.

Kennispark, meanwhile, has been a peripheral element in national economic strategy in the Netherlands. Here, the internal politics of economic development saw particularly adverse consequences of deindustrialisation for a number of outlying regions distant from the Randstad in the 1990s. Each of these regions acquired its own regional development agency, but at the same time, a national spatial planning imaginary emerged claiming that the success of Netherlands as an internationally competitive trading partner was built on two pillars, the North and the South wings of the Randstad, corresponding to the two 'Mainports' of Amsterdam Schiphol Airport and the Rotterdam Shipping Harbour. The Mainports concept embodied a range of ideas, and captured the planning imaginary to the point of completely dominating the fourth national spatial plan by the 1990s. This made it extremely difficult for the peripheral regions to define their own strengths, and as the liberal government shifted towards a more supply-side economic policy, peripheral regions faced a threat of being defined as costs for the Netherlands in contrast to the benefits brought by Amsterdam and Rotterdam.

While some Dutch regions were able to successfully challenge this positioning, including for example Brabant (in particular around the site of the Philips factory in Eindhoven which reinvented itself as a 'brainport'), in national terms Kennispark has remained a peripheral node in a wider knowledge trunk infrastructure. There are not strong business champions for Twente as an innovative region, in the way that Philips and its spin-offs are clearly cheer-leaders for Eindhoven and Brainport. 
Kennispark itself has tried to build (and publicise) linkages with external high-technology R\&D leaders as well as benchmarking itself against other technology regions. The University of Twente is a member of the European Consortium of Innovative Universities, all technology universities in potential growth regions and the consortium has started recently to place more emphasis on the regional engagement and development activities of its members. However, despite the lobbying efforts of local policy-makers at all levels from municipality to the province, the sense of peripherality in the national arena remains.

\section{Science 'Scapes and International Scientific Identities}

Having established the contexts in detail, in Sections 3 and 4 we extend Appadurai's dual focus on perception/perspective and identities to tease out the notion of science spaces as ethnoscapes, taking the question of international scientific identities first. Here, the dynamic and complex interweaving of ideoscapes and technoscapes outlined above forms the backdrop for very particular forms of identity-creation. We therefore focus on a number of aspects, including: the basic nature of various scientific endeavours, respective positions in global divisions of labour; work structures, organisation and practices; processes of collective imagination and community organisation; and affective influences such as personal biographies and emotional connections. Once again, we present the cases in turn, given the complex and highly distinctive conditions in each case.

\subsection{Science Vale Oxford}

At the heart of scientific identities in SVO is the fundamental science undertaken in the big science installations. The nature of the science conducted here establishes a very specific context in terms of the requirement for fundamental academic research, the objective-driven nature of the endeavour, the time horizons over which experiments are designed, programmed and implemented, and the nature of the outputs produced. The corollary of this is that such activity is seen as necessarily international, integrally linked to the outside world rather than 'contained' in any particular site or installation. In part this reflects the quite literal construction of international scientific projects and associated scientific communities, with JET, for example, from its inception an international enterprise, drawing together expertise from across the partner nations, and Diamond, though conceived as a national facility, intimately tied into a European and indeed global synchrotron community, where skills would be drawn from across this global context and users of synchrotron beamlines-both domestic and international-would have access to varied international and national facilities across Europe and the world.

Of course, the international nature of fundamental science has been reflected historically in the sharing of letters and information amongst leading scientists and in the general conception of science as basic human endeavour, not amenable to national boundaries. But it is extended dramatically in the context of globalisation and the rise of knowledge-based, digital economies. An interview respondent at Diamond commented forcefully in these terms:

"Science is international. Top science must be international. You cannot put borders on that, or employ only British scientists - it will not work. At the end of the day that is the baseline. If we want to claim that we have international level science then we need to employ international people and have users from abroad". (Interview, 11.7.16)

This is particularly important because it underlines the identification of migrant scientists at these installations as international scientists per se, part of broader scientific movements associated with their overall fields and tied into networks around their particular areas of specialism. This separation into specialisms is naturally characteristic of big science projects, where the scale and diversity of the enterprise requires organisation into discrete teams, which reach out to and are part of associated international communities. In this sense they belong to 'global villages', based for example around the 
specific techniques being developed to exploit particular synchrotron beamlines or engaged in one or more of the multiple scientific and engineering specialisms that make up fusion science.

Often important to the construction of identity amongst migrant scientists in big-science facilities is the opportunity to create, to (literally) build new facilities or capabilities, to be part of a grand project, and to exploit more fully skills developed elsewhere-to go through, perhaps, what Andrew Pickering [36] termed the 'mangle of practice'. There was a notable commitment to the overall ambition of projects and being part of the instigation and development of scientific experiments and entities, giving rise to new and distinct communities in line with Appadurai's [9] 'production of locality' where actors collectively imagine and create new social realities. At Diamond, for example, an international specialist in infra-red microspectroscopy described his move to the facility in 2006, starting with just a 'hole in the wall' and tasked with building a phase 1 beamline and constructing a team to exploit the research:

"Starting in a project in the construction phase - building it from scratch - is a dream for a physicist like me. You can build your own instrument, you can design it, construct it, commission and use it in doing research. It's a dream for us. And on the other hand these facilities, in terms of research, are really international. What I'd learned in my previous job immediately translated here because the method and the technology was the same. So I see the benefit for myself of applying things here - partly for my benefit, but also a national facility like this took benefit from my knowledge and know-how." (Interview 19.7.16)

In producing distinctive international communities, and identifying particularly as international scientists, migrant scientists nonetheless retain a clear sense of their own biography and history, even if they are fully settled in the UK. This tends to sensitise individuals to the idiosyncrasies of working styles and organisation in their respective facilities and in British science more generally. Work cultures were broadly perceived as relatively open and less-hierarchical arrangements, with some notable degree of informality, albeit within fairly rigorous organisational and operational environments. There is also a sense of British pragmatism and a focus on the achievement of outcomes rather than the formalities of procedure. Interviewees registered some feel for British 'reserve' with international incomers and visitors tending to be left somewhat to their own devices, to find their own way. With high proportions of international staff, working relations in the big science installations need to be cognisant of national cultures, styles and sensitivities, and working languages and styles tend to be adapted somewhat to operate in an international context. These differences are a question of degree, however, rather than fundamental differences in working practices from big-science installations in other nations. Crucially, though, while identifying as insiders in European and global scientific communities there is a retained sense of distance and outsider identity in terms of their status in Britain. Migrant scientists did not identify themselves in relation to British science or to British nationality (even if they had become British nationals), but rather reflected on the British reputation for tolerance of incomers, on the quality of life and services available in this generally privileged part of England (Britain seen as generally a 'safe-bet'), and on the international flavour of the area built upon the science base. In this sense Britain is perceived more generally as host rather than form of identity, even by longer-term migrants, though the underlying sense of global connection is evident

Against this background - of identification as international scientists per se, and of Britain as host for international big-science projects-we must note that the Brexit decision in the June 2016 referendum on EU membership was seen as especially disturbing for migrant scientists. For not only did the decision engender major uncertainty over European funding streams for research and the active involvement of British scientists and teams in future European projects, but it also went to the heart of the international scientific identities constructed by migrant scientists. For many interviewees the latent sense of outsider status was - to varying degrees - activated by a 'Leave' campaign which was perceived as discomforting at best, and more generally as somewhat aggressive and misinformed. While most respondents expressed confidence in the importance and future of their research there was 
a sense also that something major had occurred with the Brexit decision and that Britain as host had immediately a different feel.

\subsection{Tsukuba Science City}

Earlier work by Sharon Traweek $[30,37,38]$ as part of a global programme of research at major national high energy physics laboratories provides vital insight into the nature of scientific identities as they emerged in TSC, focusing particularly on KEK. This stressed the relative marginality of scientific identities at KEK in global terms and also the outsider status of the scientists involved, characteristics which were magnified for international scientists in particular. Traweek noted, for example:

"The high energy physicists in Japan work at the margins of two empires: the international scientific community, which is based in North America and Europe, and the Japanese scientific community, which is based in the universities and the Ministry of Education. A few high energy physicists used that bachigai outsider position to build Tsukuba Science City, Tsukuba University, and KEK, the Japanese National Laboratory for high energy physics. They accomplished this through strategic use of gaiatsu foreign pressure, among other strategies, and made the most of the Japanese public's and government's concerns about kokusaika, Japan's national identity in global politics. By building a national laboratory with state-of-the-art research equipment they vastly increased their status in the international scientific community, but that community is still centered somewhere else. Japanese scientists now wield some power in that international high energy physics community, but few American or European physicists have yet bothered to learn about the political economy of big science in Japan". [38] (pp. 49-50)

Japanese physicists who worked in TSC and at KEK at that time were aware that these institutes were somewhat outside of the control of Japanese university physics community, with a consequent attraction to a loyal band of returnees who identified that they were 'a bunch of oddballs and out of place' [30] (p. 457). And while the Japanese needed foreign researchers to gain credibility in the international high energy physics community, foreign scientists among them were afraid of losing status within that community just by being there [30] (p. 451), joking about it as a 'high risk-high gain' move in career terms.

Despite the undoubted presence of TSC on the global map of science spaces, these aspects of relative detachment from the global scientific mainstream and from Japanese society more broadly continue to inform international scientific identities. Indeed, TSC represents a concentration of institutes, laboratories and international scientific labour which has been, and to an extent continues to be, somewhat peripheral in global terms. For example, while KEK in particular subsequently gained prominence (Notably Emeritus Professor Makoto Kobayashi at KEK was awarded the Nobel Prize in 2008) it continues to occupy a secondary position despite being the second biggest institute after CERN in Switzerland because in particle physics experiments such as Belle I and II (with 700 participants from 25 nations) it represents a lower energy physics experiment alternative to the much larger and much better funded high energy physics philosophy of CERN. A KEK interviewee noted, for example:

"In particle physics nowadays just CERN is more than half of the community and most younger people are attracted by the scale of the project it is more than natural to have a dream to work there."

(6 June 2016)

More broadly here, the most recent survey of foreign researchers in TSC [31] (p. 5) indicates that with 1781 researchers by far the largest group are Chinese (33.7\%) and that the majority of researchers are from the East Asia region including China, Taiwan, South Korea, Vietnam, and Thailand (53.5\%) with researchers from the UK and USA accounting for only $4.8 \%$. Our own research suggests that the international scientists found in TSC tend to be associated with specific contacts and particular experimental designs, and are rather self-selecting, in contrast to the overall sense of global integration evident in SVO. 
The 'outsider' experience of international scientists at TSC is reinforced by a national culture of scientific research which has historically been less open in Japan than elsewhere, though that in TSC compares favourably with elsewhere in the country (Interviewee, NAIST, 9 June 2016). This may reflect a specific research environment established at the outset which, despite some limitations, is rather unlike elsewhere in Japan. The University of Tsukuba, for example, was not organised in the same way as other Japanese universities and recruited at the outset in a more open way [19] (p. 456). However, despite the undoubted and unique mixing of nationalities in TSC, the gaps in communication previously noted by Hall and Castells [29] (p. 72) among different groups of students and scientists and even among research institutes appear to remain. As the largest group, it was little surprise that the Chinese contingent in TSC forms the most cohesive community, though organisation here remains informal (Interviewee, Tsukuba Center Inc., 6 June 2016).

One important dimension rehearsed in interviews was the hierarchical organisation of research compared to other national contexts, which then extended into a lack of communication about what research leaders and line managers were doing and, by the same token, a consequent need to cultivate relationships within the workplace in order to get things done:

"The culture ... it's completely different. In the Netherlands it is much more direct. If you have an idea, it doesn't matter who you are, you can just say your idea to anyone, and discuss it and improve it and maybe manage it. But here it is more like a pyramid, hierarchy... Relationships are the key to getting any project started. If you need funding or if you need to consult with an expert you never go directly to the person in charge. You have to go to someone you know who knows someone that they know ... you can't go directly." (Interviewee, Public Works Research Institute, 9 June 2016)

For others, though, the hierarchical organisation of research into specific tasks also generated a degree of freedom and autonomy for individual teams that was appreciated even if it displaced broader opportunities to discuss the overall findings from research (Interviewee, KEK, 6 June 2016). Beyond this, generalisations across the many different institutes found in TSC can be more problematic. Instead, research culture often appears to depend on the director of each specific institute, with two distinct aspects to this: First, directors are drawn from two different pools-government ministries or academia-the accusation being that the former are poorer managers of researchers and the research process compared to the latter (Interviewee, Public Works Research Institute, 9 June 2016); and second, the orientation of academic directors themselves can differ significantly depending upon their international experience (Interviewee, NIMS, 26 September 2016).

The marginality which informs international scientific identities in Tsukuba is inflected by distinctive cultural forms. Specifically, the relatively closed nature of Japanese science and society more widely sharpens the experience of scientific immigration and work, often resulting in a relatively short-term sojourn for scientific migrants. This pattern of transience is reinforced by a context in which non-Japanese scientists remain predominantly outsiders or guests, faced with highly-restrictive immigration policies, general ineligibility for naturalisation, and social attitudes which tend to marginalise incomers, as well as the language barrier [39] (pp. 14-15). The rather aptly-named 'Alien Times' (http:/ / www.alientimes.org; see also TsukuBlog at: http:/ /blog.alientimes.org/), a monthly English newsletter published in Tsukuba since 1987 (online at since 2002), has carried articles regarding international experience in Tsukuba, respondents remarking that the city was 'a closed domestic village', that Ikebana (flower-arranging) and tea ceremony lessons tended to be oriented towards Japanese people rather than foreigners, and that institutional supports, for example through the Tsukuba Information Centre, the City and the Prefecture, could serve a greater purpose in the lives of foreigners in the city.

\subsection{Kennispark}

The primary identity of international scientists within Kennispark was as knowledge migrants who had come to Twente for a period of time to pursue an academic career via the University. 
While most of these were attracted by UT's research institutes and opportunities (e.g., MESA+Nanolab, part of the NanoNextNL national research program for nanotechnological research and innovation), others arrived in the Twente region coincidentally or via their supervisors' personal research contacts. But at the same time there was a recognition that their local professional networks within UT and Kennispark were important in defining who they were and what kinds of research areas they were interested in. Indeed, migrants to Kennispark identified its innovative entrepreneurial profile as a space that encourages young entrepreneurship and applied science (Interviews 5 Oct 2015, 17 May 2016).

A number of specifically Dutch, Twente and Kennispark identity elements could be glimpsed in the ways that respondents spoke of their work experiences. In particular, international knowledge migrants related to Kennispark as an 'entrepreneurial' knowledge park. In some cases, this was explicitly related to UT's long-standing description as 'the entrepreneurial university' and the specific start-up creation programmes available. The university offered international migrants the ready routines and opportunities to exercise an entrepreneurial identity in the course of their scientific lives, which saw for example one international knowledge migrant who had lambasted the 'poor food-poor weather experience' of living in the area start a company and apply for a highly prestigious European research council grant. But other elements of entrepreneurship (social and institutional) were also evident in the reported identities, with respondents talking of the space and latitude they had to recognise opportunities, build local activities exploiting their wider international networks, and create activities. In some ways this emphasised a placelessness and footlooseness that was part of the reported experiences of the migrants, who could use Kennispark as a launch-pad or step on a longer journey. It was telling, perhaps, that one respondent stated that he and his wife are used to moving to different places on a three to four-yearly basis and that they have built up a 'survival instinct' as well as 'coping strategy' to deal best with these kind of situations (UT researcher, May 24, 2016, p. 4).

Allied to this entrepreneurial flavour was an acknowledgement of the distinctive nature of the Dutch working environment, and of the formative influence this played on migrants' enactments of scientific life. Several interviewees described Kennispark as a place that exhibits a strong 'Dutch culture', with flat communication lines and informal relationships, highlighting that they appreciate the informal aspect of networking. International migrants were themselves active participants in constructing this culture, recounting innovative ideas and news being created and discussed during coffee breaks, corridor discussions and informal conversations. This was seen by some as itself conducive to good science with discussions being less emotional, more rational and interactive, with a shared identity of approachability, open-mindedness and critical thinking.

Also, a further element of local identity emerged from the characteristics of the region and the Province, in the way that migrants were fully aware that they were not in the cosmopolitan heart of the Netherlands, the Randstad. Amongst a range of comments here a corporate scientist remarked, for example, that the working environment was more convivial and less demanding than his previous metropolitan context (Interview 24.6.16), with interactions being far more personal and less directive, something that had required him to adapt. Peripherality here was associated with a sense of collectivity, the space and time to be more interactive, based in part on a higher mutual interdependence of community members.

\section{International Perceptions of Technoscapes}

\section{1. $S V O$}

Appadurai's concept of 'technoscapes' suggests a broad engagement with mobilities amongst various forms and levels of technology, financial and political resources, and also different types of labour. In turn, the particularities of technoscapes "are increasingly driven not by any obvious economies of scale, of political control, or of market rationality but by increasingly complex relationships among money flows, political possibilities, and the availability of both un- and highly 
skilled labor" [8] (pp. 297-298). The implications of this become particularly apparent with regard to immigrant scientists' perceptions of the technoscape of SVO. Here, in the context of big-science installations the primary features are the world-class or world-leading nature of the facilities, the scale and quality of the technological kit, the profile and quality of leading scientists, and the profile of the projects within their respective European and global communities. The scale and scope of the installations certainly reflects complex decision making across European and national governments, significant international flows of investment and research funding, and critical contributions from international scientific labour. In addition, these particular types of projects create a powerful physical and organisational presence.

Yet the primary focus on technology, machinery and world-leading scientific labour amongst our international scientific respondents stands in notable contrast to the particular messages cultivated by science park managers, developers, central governments and local authorities, where architectural forms, image-marketing, and economic development possibilities are key considerations. For international scientists the architecture per se was of limited importance, and built forms were not substantially different from what might be found at similar big-science facilities elsewhere in Europe, Asia, or North America. While sites such as Culham are perhaps less 'shiny' than some other examples around the world, the facilities were seen-at least in some instances - as more modern and comfortable than some other comparable sites, and similar in terms of their ex-urban location.

That said, the built form does to some extent colour the day-to-day experience and the nature of work, at Culham, for example, where the sense of separation between specialist teams is to some extent replicated and reinforced by the physical separation of particular buildings and corridors which provide for only limited interaction, or at Diamond where a more open and transparent built form seems to allow for more immediate communication. At both JET and Diamond shared areas such as the control rooms, meeting spaces and the canteen and coffee bars provide occasions and areas where people come together, but overall the sense of shared space and social setting is a relatively small part of the physical context. Broadly, the 'feel' of the facilities is probably somewhere between that of university and industry, clearly not commercially-oriented, but also obviously more project and goal-oriented than a purely academic institution.

In terms of relations with the local and regional science-base in Oxfordshire and the surrounding region, what was immediately apparent in interviews was the principal focus of scientists on their own projects and specialist fields. Interestingly, for most respondents there was very little sign at all of cross fertilisation of activity between Harwell and Culham, though some joint working between Diamond and the neighbouring ISIS pulsed neutron and muon source was reported. To some extent there were also linkages with the local business community in Oxfordshire, particularly in the life sciences sector. However, the more general sense, very clearly, was of a perceived 'technoscape' formed by the immediate working environment of the individual scientist and their associated international and national networks, rather than a sense of Oxford or Oxfordshire as science-scape, despite the obvious presence of the University of Oxford.

To some extent this very focused perception of the technoscape chimes with the wider challenges of establishing coherence amongst the SVO areas which we have highlighted elsewhere [40,41]. Also, here, in similar vein, there was little immediate sense amongst international scientists of how the UK Government projects SVO and its constituent areas as a means of international diplomacy, economic development, inward investment promotion, and place marketing, though there was clear commitment to a strong programme of outreach to schools and the local community in terms of education, training and general publicity. This is not to say, however, that scientists had no views on the wider operation of the area and the importance of place. Though this was always secondary to the core scientific and technological aspects, the quality of the local environment, the style of life, relatively easy access to both Oxford and London and associated cultural attractions and connections made for a view of this part of England as a reasonable place to live and do scientific work. Combined with the quality of the 
scientific facilities, and the international community of scientists collected in this area, there was an evident draw for many individuals.

\subsection{Tsukuba}

Despite the sleek, monumental, and international flavour of the architecture of TSC, the sense of marginality described above with regard to international scientific identities is clearly associated with broader aspects of the technoscape: its relatively closed atmosphere in global terms, its secondary position in certain key global scientific communities, the more limited profile of some key facilities vis-à-vis world-leading projects and facilities elsewhere, and its primarily national, ethno-centric (rather than geocentric) organisation and development goals.

Against this background, international perceptions tend to reinforce Gonzalez-Basurto's [22] (p. 15) prior claim that 'Tsukuba Science City has gained international prestige for what it is best known, a mirror image of the omnipresence of the Japanese national state'. Indeed, TSC represents primarily a conglomeration of state-sponsored science institutes and a distinctly Japanese endeavour, rather than an internationally-oriented project directed towards enhanced integration into the global economy. Moreover, the physical resemblance to ICGS forms does not compensate for a lack of soft living amenity and welcoming culture to international scientists. Interviewees remarked, for example, on the 'cold-blooded, artificiality' of TSC (Interview, 1st June 2016), the poorly developed community support for foreign scholars and scientists, and the challenges of socialising and integrating with Japanese colleagues.

In many ways the cultural distance experienced by international scientists at TSC is mirrored by its physical remoteness within the Japanese urban system. Located in rural Ibaraki prefecture it was a curiosity considered hardly part of the core of urban industrial Japan. Traweek [19] (p. 457) previously drew attention to some of the uniqueness of Tsukuba Science City:

"Underscoring their isolation from the conventional sites of power, the science city is located in Ibaraki, an economically depressed region which has the reputation among sophisticated Tokyoites of being hopelessly déclassé."

As if to reinforce this remoteness, researchers in TSC selected names for their locations and facilities that represented the marginality of this science location and to an extent the global marginality of the experiments being conducted:

"Instead of identifying themselves with places all Japanese would recognize as imperial sites, they just used a local, inconsequential place-name, knowing that to other foreigners in the international scientific community all the names ... would be inconsequential. It was a joke about the marginality of the whole place. " [19] (p. 450)

Overall, then, in spite of the scale of developments that have occurred at TSC, the picture of marginality and remoteness seems to persist with scientists working in the city. Though different nationalities do mix to some extent, Tsukuba is not cosmopolitan, one interviewee remarking that his colleagues have described it as 'the most boring city they have ever been to' (Interviewee, KEK, 6 June 2016), and referencing the remoteness associated with isolated big science facilities. A Chinese scientist who had studied and worked in TSC since 1989 further recalled the anecdote that there are two types of people in Tsukuba-farmers and doctors (Interviewee, NAIST, 9 June 2016). The general sense, then, is of a technoscape which is perceived as marginal to the global mainstream, and where a degree of cultural remoteness is experienced in particular ways by international migrants.

\subsection{Kennispark}

While some international knowledge migrants were surprised at the fact that prestigious scientists from their field of science were working in research institutes at the UT, many stated that they were attracted to UT's strong experimental and applied focus in research as well as to its good 
established relationships and research collaborations with industry. Emblematic here was a UT migrant who appreciated Kennispark as an interactive space environment, where it was possible to 'meet practicing entrepreneurs almost daily, because they [are] located right across the street' (Interview, UT, 17.5.16). Interview evidence further confirmed that the UT and its research institutes were also seen by international enterprises as a valuable and unique knowledge producer for enterprises' R\&D centres (Interview, company employee, 24.6.16). Due to close inter-relationships and research contracts between enterprises and UT research groups and individual researchers, new materials and technologies can be developed and tested in UT research facilities.

However, although international migrants recognise and value the existing relationships between enterprises and the UT with regard to research, Kennispark as such is often perceived as a "mythical and vague place" (UT researcher, October 6, 2015, p. 3). Indeed, the general perception amongst the international knowledge community at Kennispark has been of a rather provincial place in the periphery of two small rural towns. Efforts to create a stylised and attractive environment with research and funding opportunities are positively perceived, though the majority of interviewees did not recognise a functional Kennispark architecture. Although the creators of Kennispark aimed to create proximity through new built forms, knowledge-transfer through personal relationships and community ties between both sides of the park is still seen to be relatively limited. Moreover, the physical disconnection that existed between both sides of the park initially hampered efforts to establish a kind of innovative milieu [42] where actors were able to cooperate and exchange. Various efforts have subsequently been made to establish a visible university-industry linkage, in which existing purely academic facilities (e.g., former laboratories) located at the campus were reconstructed to shared academic and corporate facilities. Also, to encourage interpersonal interaction and knowledge exchange between both sides, architects tried to provide Kennispark with a virtual space-architecturem, thereby integrating business facilities in the old campus environment to bind people to specific places and lead them around the Kennispark unselfconsciously.

As a further step to counter the provincial flavour, UT has also strived towards more internationalisation, standardising the previous educational system into a bachelor/master system and working towards the objective to offer English-speaking bachelor and master programmes only. To enhance its position in global production networks, the Kennispark organisation established an intensive knowledge exchange with managing directors in Silicon Valley, and since 2008, delegations staffed with representatives of the municipality, Kennispark enterprises, media (Oost NV), the Chamber of Commerce, and the UT have visited Silicon Valley on a two-year basis, followed by revisits from the Silicon Valley delegation. Additionally, UT hosts festivals, career-related events and national sport events on the Campus to establish a more attractive and popular environment for Kennispark, and invites well-known Dutch personalities and politicians. There is also a sense in which the attempt to build a complex social system, with shared symbols integrated in a self-leading virtual campus infrastructure, gradually creates for some international migrants a place related attraction and a sense of belonging to a place related identity [43].

\section{Conclusion: Science Spaces as Comparative Ethnoscapes}

In this paper we have examined how three particular science spaces have been imagined and experienced particularly as 'ethnoscapes'. Following an historical review of the technoscapes and ideoscapes as they have evolved at each site, we have sought to crystallise emergent international scientific identities and perceptions/representations as two key inter-related dimensions of the respective ethnoscapes. Thus, SVO is characterised by a distinctive sense of international scientific identity, tied into broader scientific movements and global networks of scientific specialism, with perceptions of the technoscape coloured by world-leading technologies, personnel and scientific profile rather than particular architectural or real-estate formatting. TSC, in contrast, conceived as an embodiment of Japanese development ambitions from the mid-1960s and a central part of the national-development ideoscape, retains a sense of marginality in the global arena. This is reflected in 
individual scientific identities and reinforced on the one hand by issues of nationality, language and work culture, and on the other by a sense of physical and cultural separateness within Japan. Yet this is despite its undoubted importance as a science centre, its dominant position as a locus for Japan's public research and development expenditure, and its architectural scale and form. Kennispark, meanwhile, is more provincial in terms of identity and perception/representation, primarily engaged in smaller-scale and more commercial and entrepreneurial scientific endeavour-albeit with potentially global commercial reach - and somewhat outside the national ideoscape in the Netherlands. International scientific identities here tend to be entrepreneurially-oriented, somewhat more loosely-formed than in the comparator cases where 'big' and institutionalised scientific activity is more prevalent, and coloured by Dutch working culture and the provincial setting.

Drawing on Arjun Appadurai's conceptual architecture provides important insights here. First, it provides a conceptual starting point for examining science spaces as multiplex entities, simultaneously as major physical and technological forms, expressions of political and symbolic capital, key elements of local, regional and national planning policy and economic strategy, and sites of international labour movements and knowledge transfer. Thus, we have sought to engage these multiple dimensions-technoscapes and ideoscapes, alongside ethnoscapes-recognising that Appadurai's model not only offers multiple flows and 'scapes but also insists on their empirical and analytical separation and the potential for disjuncture between them. This, in turn, provides a clear rationale for the focus on differentiated transnational movements, of development styles and processes, technological forms, political-diplomatic messages, and scientific labour, and also for important interactions and relations between these movements. Adopting the 'scapes approach thereby sharpens our sense of the 'international-ness' of science spaces, in its various dimensions, illustrating for example, that global flows of labour, technological capacity, architectural styling and diplomatic power are highly distinctive.

Secondly, the approach enhances our sensitivity to differentiated perspectives on these forms and flows. In straightforward terms, working with the notion of 'scapes helps us to position ourselves from various viewpoints in asking what it means for various actors to live and work in and around science spaces, to develop new technologies and create new scientific discovery, to generate and represent particular communities, and to assimilate into a broader context. Importantly, it legitimises a focus on individual perspectives, identities, experiences and interpretations, following Appadurai's emphasis on the individual actor as the last locus of a perspectival set of landscapes. Given the present focus on science and technology spaces as ethnoscapes, scientists and technologists are the agents who both experience and constitute larger formations, building on their reading of the potentialities of varied and interacting 'scapes. Here the distinctive position and experience of migrant scientists in particular sharpens the sense of how such identity is constructed and what it might mean, reflecting, it might be suggested, Appadurai's privileging of transnational actors and their distinctive viewpoints. In short, the questions of identification and perspective are somewhat more immediate and perhaps thrown into sharper relief for migrant scientists and technologists vis-à-vis their domestic counterparts. This standpoint helps in terms of interrogating scientific identities that emerge, and importantly allows for a softer focus on individual identities, perception and experience which hasn't previously been fully developed in writing on science spaces.

Finally, some brief comments on future research directions. As the opening section of this paper made clear, the task here has been to provide an initial framing conceptualisation of 'science spaces as ethnoscapes'. In developing the analysis, we have therefore drawn substantially on Arjun Appadurai's formative statements around the concept of 'scapes, in order to demonstrate the value of this general heuristic. However, Appadurai's formulation operates at a high level of abstraction and there are limits to its explanatory and analytical purchase in interrogating cultural forms. Future research on transnationalism and scientific labour movements would undoubtedly benefit from a much wider engagement with the cultural studies and cultural geography literatures including around questions of representation and communities of practice, as well as interesting new contributions examining 
the inter-relations of mobility and creativity [44]. We are also conscious that the empirical focus here on international scientific labour is highly specialised, and that comparative analysis of transational movements amongst migrant non-skilled or semi-skilled workers would be most productive.

One potential avenue for future work derives from the philosophical proposition of 'smooth' and 'striated' spaces proffered by Deleuze and Guattari [45], as the relatively smoother spaces of international scientific labour movement and knowledge transfer intersect with the striated spaces of (supra-) national state strategies, diplomatic relations, economic and scientific programmes, and physical-built environment contexts. An examination of transnational scientific labour cast in these terms would help to emphasise more clearly the processes of international mobility and associated cultural forms. In addition, it would help to dilute the sense of individual science spaces as separated individual 'containers' rather than integral elements within dynamic global systems, and thereby open up more fully questions of centrality and peripherality in global science.

Author Contributions: The authors jointly researched and wrote this paper. D.V. led research on Science Vale Oxford and drafted the paper, drawing on material contributed by all the authors. N.P. and J.T.M. undertook research on Tsukuba Science City, and P.B. and F.E. undertook research on Kennispark Twente.

Funding: The authors gratefully acknowledge the support of The Leverhulme Trust in funding the international network IN-2014-010 Global Science 'Scapes: Dimensions of Transnationalism. Additional support for research in Tsukuba was provided to Tian Miao by the Great Britain Sasakawa Foundation (No 4947).

Conflicts of Interest: The authors declare no conflict of interest.

\section{References}

1. Tejada, G.A. Mobility, knowledge and cooperation: Scientific diasporas as agents of development. Migr. Dev. 2012, 10, 59-92.

2. Fontes, M.; Videira, P.; Calapez, T. The impact of long-term scientific mobility on the creation of persistent knowledge networks. Mobilities 2013, 8, 440-465. [CrossRef]

3. Lewin, A.Y.; Zhong, X. The evolving diaspora of talent: A perspective on trends and implications for sourcing science and engineering work. J. Int. Manag. 2013, 19, 6-13. [CrossRef]

4. Wagner, C.S.; Park, H.W.; Leydesdorff, L. The continuing growth of global cooperation networks in research: A conundrum for national governments. PLoS ONE 2015, 10, e0131816. [CrossRef]

5. Bräutigam, D.; Tang, X. Economic statecraft in China's new overseas special economic zones: soft power, business or resource security? Int. Aff. 2012, 88, 799-816. [CrossRef]

6. Carvalho, L.; Winden, W.V. Planned knowledge locations in cities: Studying emergence and change. Int. J. Knowl.-Based Dev. 2017, 8, 47-67. [CrossRef]

7. Appadurai, A. Modernity al Large: Cultural Dimensions of Globalization (Vol. 1); University of Minnesota Press: Minneapolis, MN, USA, 1996.

8. Appadurai, A. Disjuncture and difference in the global cultural economy. Theory Cult. Soc. 1990, 7, $295-310$. [CrossRef]

9. Appadurai, A. The Production of Locality. In Counterworks: Managing the Diversity of Knowledge; Fardon, R., Ed.; Routledge: London, UK, 1995; pp. 204-225.

10. Wadhwa, V.; Saxenian, A.; Rissing, B.A.; Gereffi, G. America's New Immigrant Entrepreneurs: Part I. Duke Science, Technology \& Innovation Paper No. 23. 2007, pp. 1-41. Available online: http:/ / ssrn.com/abstract= 990152 (accessed on 18 November 2015).

11. Filatotchev, I.; Liu, X.; Lu, J.; Wright, M. Knowledge spillovers through human mobility across national borders: Evidence from Zhongguancun Science Park in China. Res. Policy 2011, 40, 453-462. [CrossRef]

12. Luo, Y.-L.; Wang, W.-J. High-skill migration and Chinese Taipei's industrial development. In International Mobility of the Highly Skilled; OECD: Paris, France, 2002; pp. 253-270.

13. Hao, J.; Welch, A. A Tale of Sea Turtles: Job-Seeking Experiences of Hai Gui (High-Skilled Returnees) in China. High. Educ. Policy 2012, 25, 243-260. [CrossRef]

14. OECD. International Mobility of the Highly Skilled; OECD: Paris, France, 2002.

15. Saxenian, A.L. The New Argonauts: Regional Advantage in a Global Economy; Harvard University Press: Cambridge, MA, USA, 2006. 
16. Trippl, M. Islands of innovation as magnetic centres of star scientists? Empirical evidence on spatial concentration and mobility patterns. Reg. Stud. 2013, 47, 229-244. [CrossRef]

17. Velema, T.A. The contingent nature of brain gain and brain circulation: their foreign context and the impact of return scientists on the scientific community in their country of origin. Scientometrics 2012, 93, 893-913. [CrossRef]

18. Royal Society. Knowledge, Networks and Nations: Global Scientific Collaboration in the 21st Century; RS Policy Document 03/11; Royal Society: London, UK, 2011.

19. Beaverstock, J.V. The Spatial Mobility of Corporate Knowledge: Expatriation, Global Talent, and the World City. In Mobilities of Knowledge; Jöns, H., Meusburger, P., Heffernan, M., Eds.; Springer: Cham, Switzerland, 2017; pp. 227-246.

20. Somers, D.; Du, H.; Belderbos, R. Global Cities as Innovation Hubs: The Location of Foreign R\&D Investments by Multinational Firms. In Academy of Management Proceedings; Academy of Management: Manor, NY, USA, 2016; p. 17493.

21. Perry, B.; May, T. Cities, experiments and the logics of the knowledge economy. In The Experimental City; Evans, J., Karvonen, A., Raven, R., Eds.; Routledge: London, UK, 2016; pp. 32-46.

22. Esmaeilpoorarabi, N.; Yigitcanlar, T.; Guaralda, M.; Kamruzzaman, M. Does place quality matter for innovation districts? Determining the essential place characteristics from Brisbane's knowledge precincts. Land Use Policy 2018, 79, 734-747. [CrossRef]

23. Van Hemert, P.; Iske, P.L. Framing knowledge-based urban development and absorptive capacity of urban regions: A case-study of Limburg, the Netherlands. Int. J. Knowl.-Based Dev. 2015, 6, 314-349. [CrossRef]

24. Salazar, N.B. 'Scapes'. In Theory in Social and Cultural Anthropology: An Encyclopedia; McGee, R.J., Warms, R.L., Eds.; Sage Publications: Thousand Oaks, VA, USA, 2013.

25. Johnston, S.F. Security and the shaping of identity for nuclear specialists. Hist. Technol. 2011, 27, 123-153. [CrossRef]

26. Gummett, P.; Gibbons, M. Government research for industry: recent British developments. Res. Policy 1978, 7, 268-290. [CrossRef]

27. Forsyth, A. Alternative forms of the high-technology district: corridors, clumps, cores, campuses, subdivisions, and sites. Environ. Plan C Gov. Policy 2014, 32, 809-823. [CrossRef]

28. Forsyth, A.; Crewe, K. Suburban Technopoles as Places: The International Campus-Garden-Suburb Style. Urban Des. Int. 2010, 15, 165-182. [CrossRef]

29. Hall, P.; Castells, M. Technopoles of the World: The Making of Twenty-First-Century Industrial Complexes; Routledge: London, UK, 1994.

30. Traweek, S. Border crossings: Narrative strategies in science studies and among physicists in Tsukuba Science City, Japan. In Science as Practice and Culture; Pickering, A., Ed.; University of Chicago Press: Chicago, IL, USA, 1992; pp. 429-465.

31. Ibaraki Prefectural Government 'Tsukuba Science City'. Available online: https://www.pref.ibaraki.jp / kikaku/tsushin/documents/pamphleten01201603.pdf (accessed on 1 February 2017).

32. Bloom, J.L.; Asano, S. Tsukuba science city: Japan tries planned innovation. Science 1981, 212, $1239-1247$. [CrossRef] [PubMed]

33. Gonzalez-Basurto, G.L. Tsukuba City's social landscape: Mapping hybridity and fragmentation. In Enchanting Asian Social Landscapes; Mani, A., Ed.; Swarnadvipa Publishing Ltd.: Singapore, 2014.

34. Karnebeek, A.J. Spin-Offs and the University of Twente: Sixteen Years of Experience in Incubating Start-Ups; Twente University Press: Enschede, The Netherlands, 2001.

35. Miao, J.T. Knowledge economy challenges for the post-developmental state: Tsukuba Science City as an in-between place. Town Plan. Rev. 2018, 89, 61-84. [CrossRef]

36. Pickering, A. The Mangle of Practice; University of Chicago Press: Chicago, IL, USA, 1995.

37. Traweek, S. Bachigai (Out of Place) in Ibaraki: Tsukuba Science City, Japan. In Technoscientific Imaginaries: Conversations, Profiles, and Memoirs; Marcus, G.E., Ed.; University of Chicago Press: Chicago, IL, USA, 1995; pp. 355-378.

38. Traweek, S. 'When Eliza Doolittle studies 'enry 'iggins'. In Technoscience and Cyberculture; Aronowitz, S., Martinsons, B., Menser, M., Eds.; Routledge: Abingdon, UK, 1996; pp. 37-56.

39. Lambert, B.H. Building Innovative Communities: Lessons from Japan's Science City Projects; European Institute of Japanese Studies: Stockholm, Sweden, 2000. 
40. Valler, D.; Phelps, N.; Wood, A. Planning for growth? The implications of localism for 'Science Vale', Oxfordshire, UK. Town Plan. Rev. 2012, 83, 457-488. [CrossRef]

41. Valler, D.; Phelps, N.A.; Radford, J. Soft space, hard bargaining: planning for high-tech growth in 'Science Vale UK'. Environ. Plan. C Gov. Policy 2014, 32, 824-842. [CrossRef]

42. Benneworth, P.; Hospers, G.J. The New Economic Geography of Old Industrial Regions: Universities as Global-Local Pipelines. Environ. Plan C Gov. Policy 2007, 25, 779-802. [CrossRef]

43. Gallent, N.; Andersson, J.; Bianconi, M. Planning on the Edge: England's Rural-Urban Fringe and the Planning Agenda; Routledge: London, UK, 2006.

44. Hautala, J.; Jauhiainen, J.S. Creativity-related mobilities of peripheral artists and scientists. GeoJournal 2018, 1-14. [CrossRef]

45. Deleuze, G.; Guattari, F. A Thousand Plateaus: Capitalism and Schizophrenia; University of Minnesota Press: Minneapolis, MN, USA, 1987.

(C) 2019 by the authors. Licensee MDPI, Basel, Switzerland. This article is an open access article distributed under the terms and conditions of the Creative Commons Attribution (CC BY) license (http:/ / creativecommons.org/licenses/by/4.0/). 